\title{
PREPARATION OF NANOCRYSTALLINE CELLULOSE FROM TOMATO STEM AND COMMERCIAL MICROCRYSTALLINE CELLULOSE: A COMPARISON BETWEEN TWO STARTING MATERIALS
}

\author{
NAILE KARAKEHYA* and CEYDA BILGIÇ** \\ *Department of Environmental Protection and Control, Eskişehir Vocational School, \\ Eskişehir Osmangazi University, Eskişehir, Turkey \\ *** Department of Chemical Engineering, Engineering and Architecture Faculty, \\ Eskişehir Osmangazi University, Eskişehir, Turkey \\ \Corresponding author: Naile Karakehya,nkarakehya@ogu.edu.tr
}

\begin{abstract}
Nanocrystalline cellulose was prepared from locally abundant tomato stem. Initially, chemical treatment was performed to remove the non-cellulosic constituents of tomato stem. Isolation involves a combination of acid hydrolysis and ultrasonic treatment. The shape and size distribution of the resulting NCC were determined using particle size analysis, scanning electron microscopy (SEM) and transmission electron microscopy (TEM) images. The thermal properties, surface functional groups, sulfur content and crystallinity of the NCC derived from tomato stem were compared to those of the NCC prepared from commercial microcrystalline cellulose (MCC). The morphology of NCC obtained from tomato stem has an interconnected web-like structure and the crystallinity index was calculated as $74.4 \%$. The suspension of the NCC derived from tomato stem was very stable and could be stored for at least three months without sedimentation, which was confirmed by particle size and zeta potential measurements. The economic competitiveness of NCC production is dependent on feedstock costs. As demonstrated in this study, waste tomato stem can be a good low-cost alternative for NCC isolation.
\end{abstract}

Keywords: nanocrystalline cellulose, acid hydrolysis, tomato stem, FTIR, XRD, TGA, TEM, SEM

\section{INTRODUCTION}

According to the Food and Agriculture Organization (FAO), over 180 million tons of tomatoes are grown worldwide every year. ${ }^{1}$ In the year of 2015, total tomato production in Turkey was reported as 12.15 million tons, $27 \%$ of which was grown in greenhouses. ${ }^{2}$ Greenhouse agricultural production is an important component of the economy in Turkey. Greenhouses create a suitable climate-related environment for cultivation and crop production is possible all year round. Among the possible crops (tomato, cucumber, pepper, eggplant, haricot, lettuce etc.) that can be grown in greenhouses, tomato is the primary greenhouse crop in Turkey. However, especially in the Mediterranean region of Turkey, the problems of organic residue are gaining increasing importance because of its negative impact on the environment, generating health issues and safety hazards. Tomato stem is rotten and humid and contains relatively high levels of ash. Tomato greenhouses produce an enormous amount of organic residues, around 49 tons per greenhouse hectare in a year, which are usually stacked near greenhouses, on the seashore, stream beds or in landfills and burnt after drying in the sun. ${ }^{3,4}$ Consequently, the accumulation of these residues can cause visual pollution (Fig. 1). Thus, the production of valuable organic products from abundantly available tomato stems may influence the economic growth of a country.

The most common naturally occurring polymer in the biosphere is cellulose. ${ }^{5}$ It is the main structural constituent of plant cell walls and this makes plants so strong and tough. Cellulose is a linear homopolymer composed of D-glucose units, which are linked together by $\beta-1,4-$ glycosidic bonds. ${ }^{6}$ In the plant cell walls, the parallel cellulose molecules interact with each other by hydrogen bonds between the hydroxyl groups of the glucose monomers to form a highly ordered structure called the cellulose elementary fibrils. ${ }^{7}$ These fibrils gather into bundles in one direction and constitute the structure of natural cellulose fibers. 
Bulk cellulose consists of crystalline regions and amorphous regions in varying proportions, depending on the source of the cellulosic material. Purified cellulose can be processed to obtain microcrystalline cellulose (MCC) and nanocrystalline cellulose (NCC) via isolation and extraction of the crystalline regions using mechanical, biological or chemical treatments. ${ }^{8}$ Among them, chemical treatments, such as acid hydrolysis, are conventional effective methods.' According to this approach, amorphous regions are removed by treatment with strong acids at elevated temperatures. Sulfuric acid, hydrochloric acid and phosphoric acid can be used in this process. NCC can be produced from various resources, such as recycled newspaper, waste sugarcane bagasse, corn husk, peanut shell and waste cotton. ${ }^{10-14}$ MCC has clearly bigger particle size than NCC and it is widely used as starting material for NCC production or in the pharmaceutical and food industries. ${ }^{15-18} \mathrm{MCC}$ prepared from cotton linters is commercially available in powder form. Cotton fiber is the only natural pure cellulose. Its cellulose content can reach $95-97 \%$, and its crystallinity is of about $70 \% .^{19}$

Depending on the source of the cellulosic material and the experimental technique used, different types of NCC are available. To the best of our knowledge, the isolation of NCC from tomato stem has not been reported in the literature so far. The aim of this work has been to effectively isolate cellulose from waste tomato stem by removing all non-cellulosic components and derive NCC from tomato stem cellulose and commercial MCC via acid hydrolysis. The shape and size distribution of the resulting nanoparticles were determined using the particle size analysis, scanning electron microscopy (SEM) and transmission electron microscopy (TEM) methods. Fourier transform infrared (FTIR) spectra and X-ray diffraction (XRD) patterns were obtained to evaluate the surface functional groups and crystallinity, respectively. In addition, ultimate analysis and thermogravimetric analysis (TGA) of the studied materials were also carried out. The data were then analyzed to give an overview of the various properties of the materials under study. Finally, a comparison between tomato stem derived nanocrystalline cellulose (NCC1) and cotton linter derived nanocrystalline cellulose (NCC2) was made in this study.

\section{EXPERIMENTAL}

\section{Materials}

The greenhouse tomato (Solanum lycopersicum var. cerasiforme) stem used in this study as a raw material was collected from the harvest of 2016 in Beymelek, Mediterranean region in Turkey. The name of the tomato seed, which was used in plant growth, was Trend F1, purchased from Multi Seed Co., Turkey.

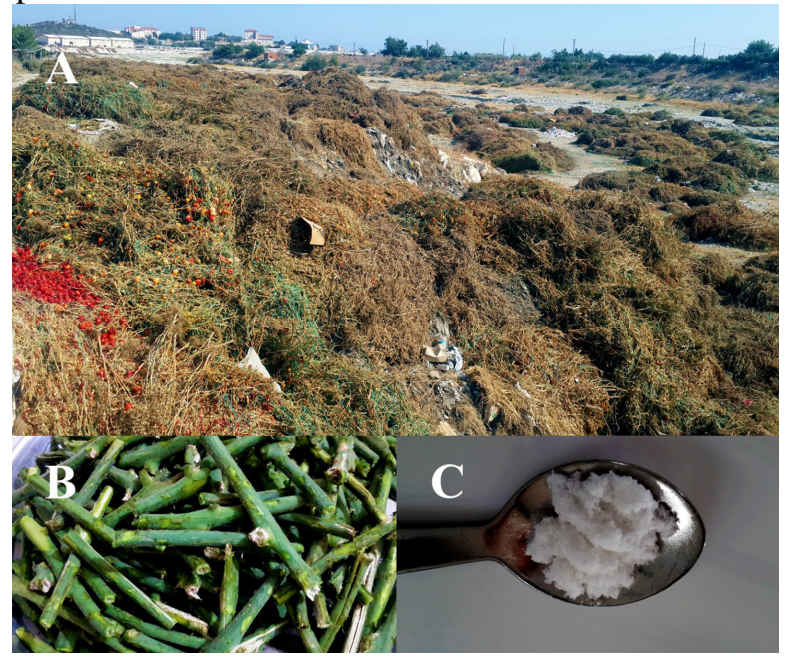

Figure 1: Picture of a tomato greenhouse waste disposal area (Beymelek, Antalya, Turkey) (A), tomato stem (B) and nanocrystalline cellulose prepared from tomato stem in this study $(\mathrm{C})$

Prior to use, the tomato stem was washed several times with distilled water, dried at $90{ }^{\circ} \mathrm{C}$ for about $36 \mathrm{~h}$ and ground in a cross-beater mill (Retsch, SK 100, Glen Mills Inc., Clifton, NJ). It was then screened to 
give a size fraction below $90 \mu \mathrm{m}$. This sample was dried again at $90{ }^{\circ} \mathrm{C}$ for $6 \mathrm{~h}$ and stored at room temperature in a glass bottle for use in the cellulose isolation experiments and was named as DMT. Extra pure microcrystalline cellulose (MCC, average particle size of $90 \mu \mathrm{m}$ ) from Acros Organics (NJ, USA) was used as reference material for the analyses and will be referred to as $\mathrm{MCC} 2$.

Benzene $\left(\mathrm{C}_{6} \mathrm{H}_{6}, \geq 99 \%\right.$, Aldrich), ethanol $\left(\mathrm{C}_{2} \mathrm{H}_{6} \mathrm{O}\right.$, Merck), sodium chlorite $\left(\mathrm{NaClO}_{2}, 80 \%\right.$, SigmaAldrich), acetic acid $\left(\mathrm{CH}_{3} \mathrm{COOH}, 99.8 \%\right.$, SigmaAldrich) and potassium hydroxide (KOH, 90\%, SigmaAldrich) were used to isolate cellulose from the tomato stem, and sulfuric acid $\left(\mathrm{H}_{2} \mathrm{SO}_{4}, 95-97 \%\right.$, SigmaAldrich) - for acid hydrolysis. All the chemical reagents were of analytical grade and used without further purification. The dialysis tubing cellulose membrane (molecular weight cut off $=12,000 \mathrm{Da}$ ) was purchased from Sigma Chemical (St. Louis, MO).

\section{Extraction of cellulose from tomato stem}

The cellulose extraction procedure was adapted from the works of $\mathrm{Lu}$ and Hsieh (2012) and $\mathrm{Wu}$ et $a l{ }^{20,21}$ A mixture of about $25 \mathrm{~g}$ tomato stem and 450 $\mathrm{mL}$ benzene/ethanol $(2: 1, \mathrm{v} / \mathrm{v})$ was stirred at room temperature for $20 \mathrm{~h}$ to ensure complete removal of wax, pigments and oils. The mixture was then filtered and washed several times with distilled water and the remaining solid was dried at $55^{\circ} \mathrm{C}$ for about $24 \mathrm{~h}$. The dewaxed tomato stem powder was then added into $1000 \mathrm{~mL}$ of $1.4 \%$ (wt\%) acidified $\mathrm{NaClO}_{2}$ solution with $\mathrm{pH}$ adjusted to 3.0-4.0 by $\mathrm{CH}_{3} \mathrm{COOH}$, and heated to $70{ }^{\circ} \mathrm{C}$ under continuous mechanical stirring for $4 \mathrm{~h}$ to remove the lignin. The mixture was vacuum filtered and washed several times with distilled water. This process was repeated four times. The straw-coloured residue was treated with $600 \mathrm{~mL}$ of $5 \%(\mathrm{wt} \%) \mathrm{KOH}$ solution at $90{ }^{\circ} \mathrm{C}$ for $4 \mathrm{~h}$. The product was separated from the mixture via centrifugation and washed repeatedly with distilled water and freeze-dried (Christ ALPHA 2-4 LD plus, Osterode, Germany). The resulting sample will be referred to as MCC1. Reduction in weight was observed after every treatment step as every step resulted in removal of some component of the biomass. The yield of MCC1 was $28 \%$.

\section{Preparation of nanocrystalline cellulose fibers}

Nanocrystalline cellulose was prepared from tomato stem cellulose and commercial cellulose by means of sulfuric acid hydrolysis. Six grams of MCC1 or MCC2 was added into $90 \mathrm{~mL}$ sulfuric acid (60 wt\%) solution and stirred at $40{ }^{\circ} \mathrm{C}$ and $110 \mathrm{rpm}$ by using a laboratory shaking water bath (Nüve ST 30, Ankara, Turkey) for $40 \mathrm{~min}$. The hydrolysis reaction was terminated by adding a 10-fold amount of cold water. The resulted dispersion was centrifuged at $7000 \mathrm{rpm}$ for $15 \mathrm{~min}$ at $10{ }^{\circ} \mathrm{C}$ (SL 8R Thermo Centrifuge, International Equipment Company, Waltham, MA) and then dialyzed with cellulose dialysis membranes against water until the dialysate became neutral. Following the dialysis step, the suspension was sonicated in an ice bath for $30 \mathrm{~min}$ and then freezedried. The collected nanocrystalline cellulose products (NCC1 and NCC2) were stored under vacuum. The denotations of samples are shown in Table 1.

\section{Characterization techniques}

The elemental analysis of DMT, MCC2, NCC1 and NCC2 was performed on a Leco CHNS-932 (St. Joseph, MI) elemental analyzer. The ASTM standard test procedure was applied for determining the ash content (ASTM D 1102-84). Thermogravimetric analysis (TGA) was carried out using a Perkin Elmer Pyris 1 thermoanalyzer (Waltham, MA, USA), under flowing nitrogen atmosphere at a scan rate of 10 ${ }^{\circ} \mathrm{C} / \mathrm{min}$ from 25 to $625{ }^{\circ} \mathrm{C}$. XRD patterns were recorded between $1^{\circ}$ and $60^{\circ}(2 \theta)$ at a scanning speed of $0.02^{\circ} \mathrm{min}^{-1}$ using a Rigaku Ultima-IV diffractometer (Akishima, Japan) with $\mathrm{CuK} \alpha$ radiation $(40 \mathrm{kV} / 30 \mathrm{~mA})$. The crystallinity index (CI) or degree of crystallinity was determined by means of Equation (1). In this equation, $\mathrm{I}_{002}$ is the intensity of diffraction at a 2-theta angle close to $22.8^{\circ}$, representing crystalline material, and $\mathrm{I}_{\mathrm{am}}$ is the lowest intensity at a 2-theta angle close to $18.2^{\circ}$, representing amorphous material in samples. ${ }^{22}$

$C I=\left[\frac{I_{002}-I_{a m}}{I_{a m}}\right] \times 100$

Table 1

Denotations of samples

\begin{tabular}{lc}
\hline Samples & \multicolumn{1}{c}{ Denotations } \\
\hline DMT & Tomato stem \\
MCC1 & Tomato stem microcrystalline cellulose \\
MCC2 & Cotton linter microcrystalline cellulose \\
NCC1 & Tomato stem nanocrystalline cellulose \\
NCC2 & Cotton linter nanocrystalline cellulose \\
\hline
\end{tabular}


Table 2

Elemental analysis data for DMT, MCC2, NCC1 and NCC2

\begin{tabular}{lccccc}
\hline Sample & Ash (wt\%) & Carbon (wt\%) & Hydrogen (wt\%) & Nitrogen (wt\%) & Sulfur (wt\%) \\
\hline DMT & 10.2 & 38.66 & 5.63 & 1.66 & 0.27 \\
MCC2 & n.a. & 42.54 & 6.49 & n.d. & n.d. \\
NCC1 & n.a. & 40.48 & 6.33 & n.d. & 0.57 \\
NCC2 & n.a. & 41.50 & 6.53 & n.d. & 0.31 \\
\hline
\end{tabular}

'n.a.' denotes 'not analyzed', and 'n.d.' denotes 'not detected'

The FTIR spectra of the DMT, MCC and NCC samples were obtained on a Bruker IFS 66/S FT-IR Spectrometer (Billerica, MA) equipped with an attenuated total reflectance (ATR) accessory containing a diamond crystal. The spectra were recorded at room temperature in a spectral range of 4000-400 $\mathrm{cm}^{-1}$, with a resolution of $4 \mathrm{~cm}^{-1}$. The particle sizes and zeta-potentials of the samples in pure water were measured in folded capillary cells using Zetasizer Nano-ZS equipment (Malvern Instruments Ltd., Worcestershire, UK), with at a scattering angle of $173^{\circ}$ and at $25^{\circ} \mathrm{C}$. The scanning electron microscopy (SEM) observation of the NCC1 sample was done by a Jeol JSM-5600 LV (Tokyo, Japan). Prior to SEM observation, the sample was coated with a thin layer of gold using a Polaron SC7620 (Quorum Technologies Ltd., East Sussex, UK). For transmission electron microscopy (TEM), a single drop of dilute solution of NCC1 was deposited on a copper TEM grid and dried overnight at room temperature, and examined by a Jeol JEM-1220 electron microscope (Tokyo, Japan, at an accelerating voltage of $80 \mathrm{kV}$ ).

\section{RESULTS AND DISCUSSION Elemental analysis}

The ultimate analysis results for DMT, MCC2, $\mathrm{NCC} 1$ and $\mathrm{NCC} 2$ are given in Table 2 (air dry basis). As observed from the elemental composition of DMT and NCC1, the carbon and hydrogen contents of the sample increased after the cellulose isolation steps, which can be attributed to the removal of ash. The sulfur percentage values of $\mathrm{NCC} 1$ and $\mathrm{NCC} 2$ were found as $0.57 \%$ and $0.31 \%$, respectively. This sulfur impurity probably originates from the sulphate groups introduced onto the surface of NCCs after acid hydrolysis. Thus, NCCs exhibited higher sulfur content than that of original materials.

\section{Particle size and zeta potential analysis}

The average value and standard deviation of the zeta potential for $\mathrm{NCC} 1$ was $-58.9 \pm 3.2 \mathrm{mV}$. NCC1 has a negatively charged surface and presents a high zeta potential value, which results in colloidal stability. The particle size distribution resulted in two main groups for $\mathrm{NCC} 1$ : $90.9 \%$ of the particles were around $235 \mathrm{~nm}$ and $9.1 \%$ were around $32 \mathrm{~nm}$. NCC2 presented narrow monomodal distribution, with an average size of $296 \mathrm{~nm}$. After a month, NCC2 slightly subsided in water, while the NCC1 suspension was maintained.

\section{XRD analysis}

Crystallinity represents the relative amounts of crystalline and amorphous regions of cellulose, where the crystalline form is dominant. It was determined to interpret the changes in the cellulose structure after physicochemical treatments (Fig. 2). It is clear that all the samples presented typical cellulose I structure, with the major intensity peak at a 2-theta value of around $22.8^{\circ}$ (plane 002) and there is no doublet in the intensity of this peak. ${ }^{23}$ The low diffracted intensity at around $18^{\circ}$ is related to the amorphous background. ${ }^{24}$ The other crystalline peaks typical of cellulose I were located around $16^{\circ}$ and $34.4^{\circ}$ for MCC2, NCC1 and NCC $2 .{ }^{25}$ The crystallinity indexes of DMT and NCC1 were found to be $56.8 \%$ and $74.4 \%$, respectively. The sharper peak and higher $\mathrm{CI}$ value of $\mathrm{NCC} 1$, compared to those of DMT, can be well understood by the removal of non-cellulosic constituents as a result of the chemical purification process. In similar studies, the crystallinity indexes of cellulose nanocrystals obtained by sulfuric acid hydrolysis of cellulose derived from corncob, sisal fibers and switchgrass were found to be about $83.7 \%, 75 \%$ and $69 \%$, respectively. ${ }^{21,23,26}$ The crystallinity indexes of MCC2 and NCC2 were found to be $83.7 \%$ and $83.1 \%$, respectively. A slight decrease in crystallinity was observed after the strong acid treatment. Sulfuric acid is the most widely applied acid for hydrolysis of lignocellulosic materials, but it is corrosive and dangerous. Possibly, low temperature, low acid concentration and short retention time should be preferred. In this way, the degradation of the crystalline domains of NCCs during the acid hydrolysis reaction can be reduced. 


\section{FTIR analysis}

The FTIR spectra of DMT and NCC1 reveal that compositional changes occur in the cellulosic biocomposite structure derived from DMT during various chemical treatments (Fig. 3). The absorbances at $1510 \mathrm{~cm}^{-1}$ and $1241 \mathrm{~cm}^{-1}$ for DMT are due to the aromatic skeletal vibration in lignin and acyl-oxygen CO-OR stretching vibration in hemicellulose, respectively. ${ }^{27,28}$ The disappearance of these peaks in NCC1 indicates that the majority of the lignin and hemicellulose have been removed from the tomato stem by the successive chemical treatments. ${ }^{29}$ The only difference between the spectra corresponding to MCC2 and NCC2 (acid hydrolysed MCC2) was in the region of $1700-1750 \mathrm{~cm}^{-1}$. The peak at $1731 \mathrm{~cm}^{-1}$ in the MCC2 and DMT samples is related to the hemicellulose. ${ }^{10}$ The absence of this peak in NCC2 indicates the partial removal of hemicellulose by the acid hydrolysis. Except this, the sample before and after the acid hydrolysis processes had almost identical FTIR spectra, showing that the main chemical composition of cellulose was not affected by the sulfuric acid treatment. On the other hand, the spectra of all the samples showed the characteristic $\mathrm{C}-\mathrm{H}$ stretching vibration around $2900 \mathrm{~cm}^{-1}$ and $\mathrm{O}-\mathrm{H}$ stretching vibration of the $\mathrm{OH}$ groups in the region of 3100$3500 \mathrm{~cm}^{-1} .{ }^{11}$ Therefore, the intensity increments of the peaks between 3100 and $3500 \mathrm{~cm}^{-1}$ in the spectrum of $\mathrm{NCC} 1$ and $\mathrm{NCC} 2$ can be interpreted as an increase in the $-\mathrm{OH}$ concentrations. Finally, the absorbance at $1200 \mathrm{~cm}^{-1}$ assigned to $\mathrm{S}=\mathrm{O}$ stretching from the sulfate groups for $\mathrm{NCC} 1$ and $\mathrm{NCC} 2$ indicates esterification of the surface hydroxyl groups during acid hydrolysis. ${ }^{30}$ This finding is consistent with the results of elemental analysis.

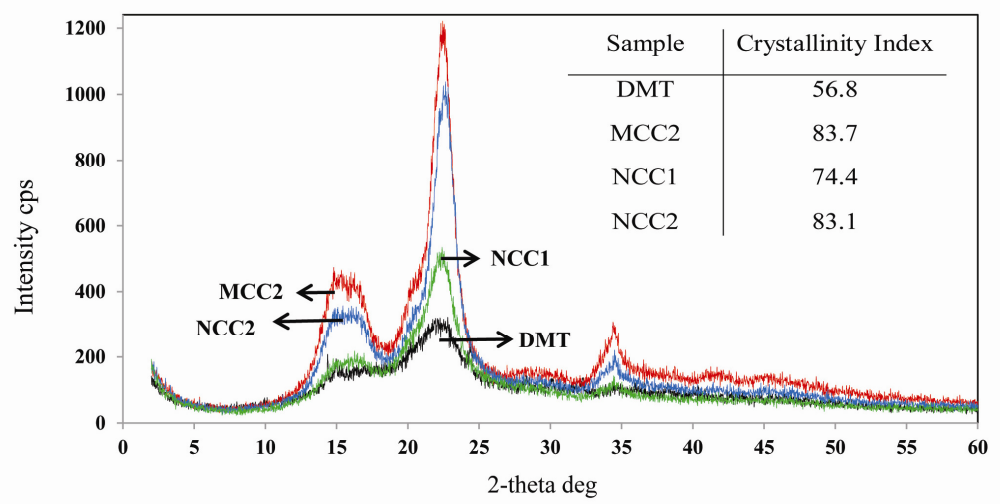

Figure 2: XRD patterns and crystallinity index values for DMT, MCC2, NCC1 and NCC2

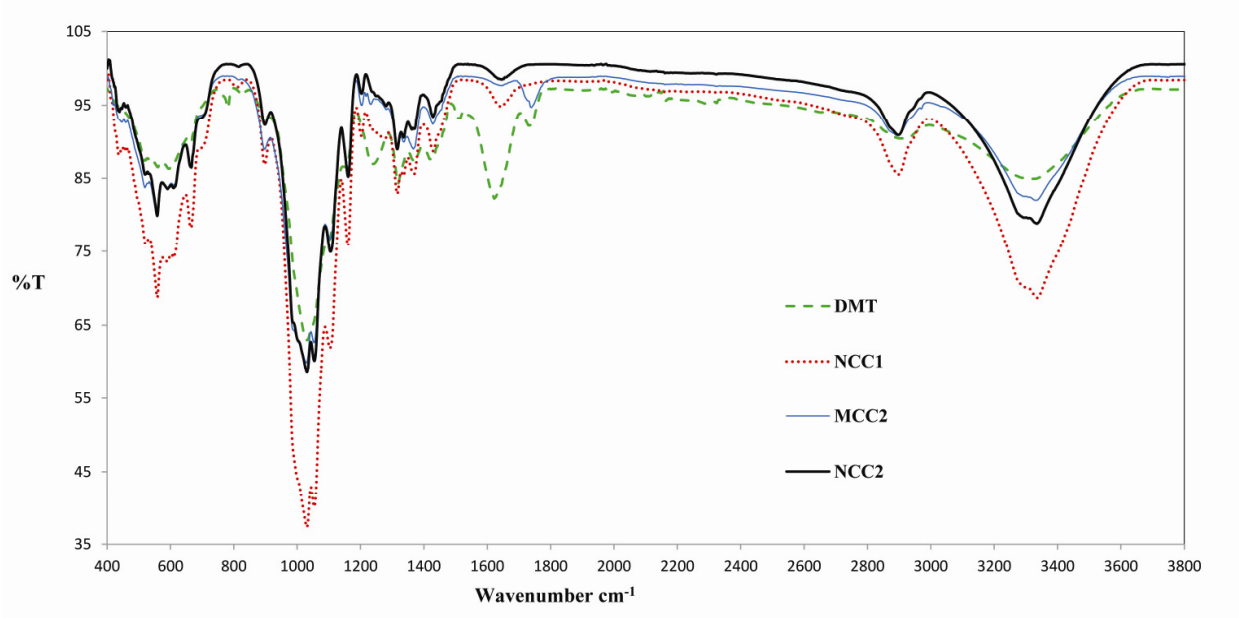

Figure 3: FTIR spectra of DMT, MCC2, NCC1 and NCC2 


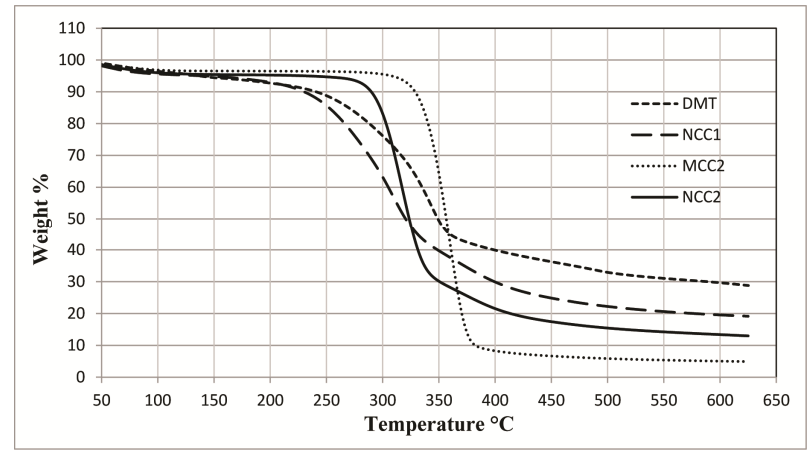

Figure 4: TG curves of DMT, MCC2, NCC1 and NCC2

\section{TGA analysis}

Thermogravimetric analysis is one of the best techniques to observe the degradation steps of cellulosic materials. Figure 4 shows the comparative thermal behavior of DMT, MCC2, $\mathrm{NCC} 1$ and NCC2. The initial weight loss found in the temperature range of $50-200{ }^{\circ} \mathrm{C}$ is mainly related to the removal of absorbed water and other volatile compounds from the samples. ${ }^{31}$ The MCC2 and NCC2 samples show a single weight loss step, with maximum degradation at about 360 ${ }^{\circ} \mathrm{C}$ and $310{ }^{\circ} \mathrm{C}$, respectively. The maximum weight loss for NCC2 occurred at a lower temperature than the maximum weight loss for MCC2. This showed that the sulfuric acid hydrolysis and size reduction render cotton linter cellulose less stable in the low temperature range. This situation can be explained by the catalytic effect of sulfate groups on the cellulose degradation reactions and the high surface area of $\mathrm{NCC} 2$, which lead to greater exposure of the surface to heat. ${ }^{32,33}$ As may be noted, three different weight loss processes were observed for DMT and NCC1 in Figure 1. The first stage, ranging from $200{ }^{\circ} \mathrm{C}$ to $300{ }^{\circ} \mathrm{C}$, basically corresponds to hemicellulose degradation. ${ }^{34} \mathrm{~A}$ small shoulder in the TG curve of DMT and $\mathrm{NCC} 1$ at $270{ }^{\circ} \mathrm{C}$ was mainly attributed to hemicellulose. ${ }^{35}$ The second step, ranging from $300{ }^{\circ} \mathrm{C}$ to $360{ }^{\circ} \mathrm{C}$, basically corresponds to cellulosic degradation. ${ }^{36}$ Finally, the small weight loss in the temperature range of $400-650{ }^{\circ} \mathrm{C}$ is mainly related to the degradation of lignin. ${ }^{35}$ NCC1 showed a significant difference from NCC2 as regards its decomposition behaviour. The degradation started earlier and finished later than that of NCC2. This was perhaps due to the incomplete removal of lignin and hemicellulose from NCC1 or to the increased sulfate content. The curves of NCC1 and NCC2 intersect at about $320{ }^{\circ} \mathrm{C}$ and $53 \%$ weight loss. Additionally, the char residue weights at $625{ }^{\circ} \mathrm{C}$ for $\mathrm{NCC} 1$ and NCC2 are of $19.1 \%$ and $12.9 \%$, respectively. This was likely due to the flame retardant behaviour of the sulphate groups. ${ }^{37}$

\section{SEM and TEM analyses}

To investigate the surface morphology at the micron level, SEM observations were carried out on NCC1 (Fig. 5). It should be noted that coating with gold would broaden the nano-sized structure and NCC particles aggregated to some extent during the long freeze-drying process. However, three different structures were observed. The first structure is very rare and composed of particles with small pores in the range of 1-5 $\mu \mathrm{m}$ (Fig. 5 A). This image reminds the capillary structure of cellulosic fibers at the macromolecular level. The nanofibrils were not pulled out from the cell wall. In this portion, the structural properties of the tomato stem cellulose were preserved, even after several treatments. The second structure is a fibrillated material, with width lower than $0.4 \mu \mathrm{m}$ (Fig. $5 \mathrm{~B}, \mathrm{C}$ and E). The third structure is the most abundant form, which is composed of laminate layers of very thin leaves with thickness lower than $100 \mathrm{~nm}$ (Fig. 5 D). Here, the clean surface confirms the removal of lignin and other extractives. The TEM image of the cellulose nanoparticles provides supporting information, indicating that a nanostructure has been formed in NCC1 (Fig. 5F). The network of cellulose fibrils, about $20 \mathrm{~nm}$ wide, is observed. Similar observations have been reported by Tang et al. ${ }^{18}$ 


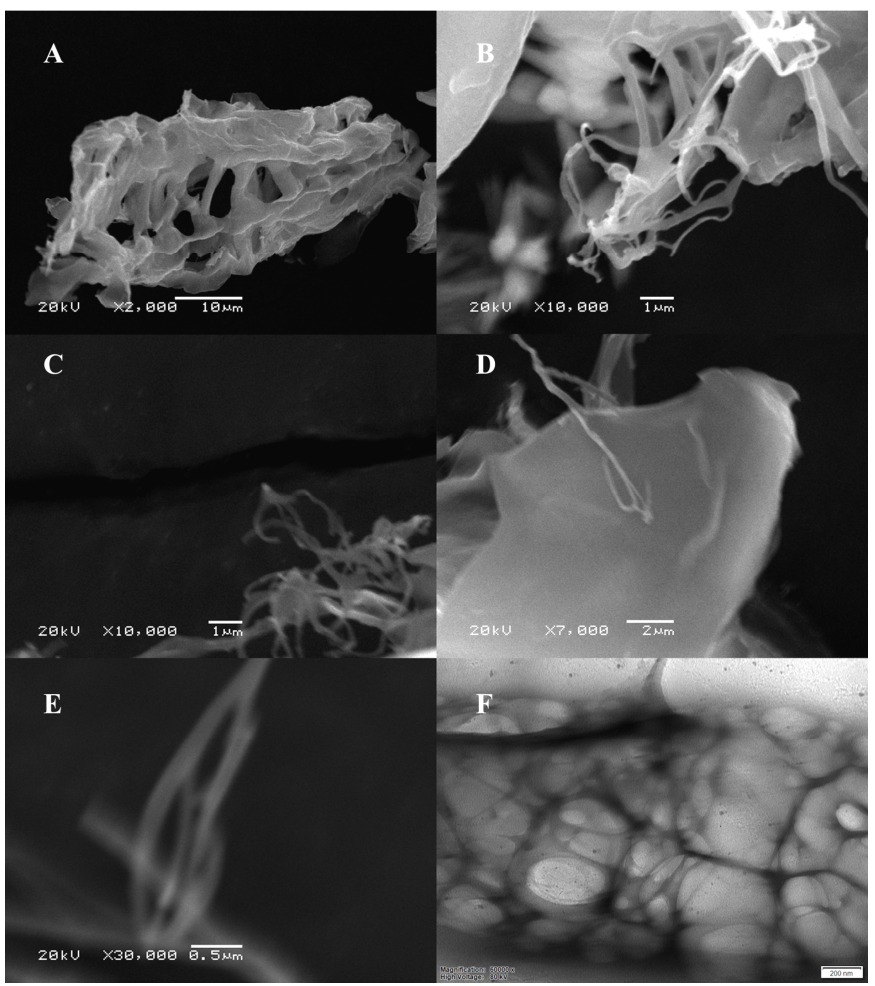

Figure 5: SEM and TEM images of NCC1

\section{CONCLUSION}

Nanocrystalline cellulose was successfully prepared from tomato stem and commercially available microcrystalline cellulose. NCC1 and NCC2 were highly crystalline in cellulose I structure. The percentage crystallinity values of $\mathrm{NCC} 1$ and NCC2 were $74.4 \%$ and $83.1 \%$, respectively. TEM and SEM confirmed the presence of nanofibrils in NCC1. The particle size studies indicate that the majority of the $\mathrm{NCC} 1$ and $\mathrm{NCC} 2$ particles lie in the nano-range. FTIR measurements showed that the chemical treatments removed most of the hemicellulose and lignin from the tomato stem. The thermal stability of NCC1 and NCC2 was investigated using the thermogravimetric analysis method. Lower thermal stability has been found for $\mathrm{NCC} 1$, in comparison with that of the raw tomato stem. The char residue amount of NCC1 was significantly larger than that of NCC2. Further studies will explore the reinforcing features of $\mathrm{NCCl}$ in nanocomposites.

ACKNOWLEDGEMENTS: This work was supported by Eskişehir Osmangazi University Scientific Research Projects Commission (Project Number: 201544004, 2015-555).

\section{REFERENCES}

1 FAOSTAT database (2019), Production/Yield Quantities of Tomatoes in the World, accessed November, 2019 , http://www.fao.org/faostat/en/\#data/QC/visualize 2 TUIK (2019), Turkish Statistical Institute, Crop production statistics. Agricultural Land and Forest Area, accessed November, 2019, http://www.tuik.gov.tr/UstMenu.do?metod=temelist 3 S. Bilgin, C. Ertekin and A. Kürklü, Akdeniz Üniversitesi Ziraat Fakültesi Dergisi, 26, 11 (2013), https://dergipark.org.tr/tr/download/article-file/17973

4 M. J. Fernàndez-Gómez, M. Díaz-Raviña, E. Romero and R. Nogales, Int. J. Environ. Sci. Technol., 10, 697 (2013), https://doi.org/10.1007/s13762-0130239-7

5 J. R. A. Pires, V. G. L. Souza and A. L. Fernando, Ind. Crop. Prod., 140, 111642 (2019), https://doi.org/10.1016/j.indcrop.2019.111642

6 C. Sánchez, Biotechnol. Adv., 27, 185 (2009), https://doi.org/10.1016/j.biotechadv.2008.11.001

L. Yan, W. Li, J. Yang and Q. Zhu, Macromol. Biosci., 4, 112 (2004), https://doi.org/10.1002/mabi.200300032

8 G. Siqueira, J. Bras and A. Dufresne, Polymers, 2, 728 (2010), https://doi.org/10.3390/polym2040728

9 A. Ramakrishnan, K. Ravishankar and R. Dhamodharan, Cellulose, 26, 3127 (2019), https://doi.org/10.1007/s10570-019-02312-4 
10 M. A. Mohamed, W. N. W. Salleh, J. Jaafar, S. E. A. M. Asri and A. F. Ismail, RSC $A d v .$, 5, 29842 (2015), https://doi.org/10.1039/C4RA17020B

11 A. Mandal and D. Chakrabarty, Carbohyd. Polym., 86, 1291

(2011)

https://doi.org/10.1016/j.carbpol.2011.06.030

2 C. A. C. Mendes, N. M. S. Ferreira, C. R. G. Furtado and A. M. F. Sousa, Mater. Lett., 148, 26 (2015), https://doi.org/10.1016/j.matlet.2015.02.047

13 B. Wang and D. Li, Compos. Part A Appl. Sci. Manuf., 79, 1 (2015), https://doi.org/10.1016/j.compositesa.2015.08.029 14 M. M. Á. D. Maciel, K. C. C. C. Benini, H. J. C. Voorwald and M. O. H. Cioffi, Int. J. Biol. Macromol., 126, 496 (2019), https://doi.org/10.1016/j.ijbiomac.2018.12.202

15 W. Li, J. Yue and S. Liu, Ultrason. Sonochem., 19, 479

(2012),

https://doi.org/10.1016/j.ultsonch.2011.11.007

16 S. Shankar and J. W. Rhim, Carbohyd. Polym., 135 , 18

(2016), https://doi.org/10.1016/j.carbpol.2015.08.082

17 D. Bondeson, A. Mathew and K. Oksman, Cellulose, $\quad 13, \quad 171 \quad$ (2006), https://doi.org/10.1007/s10570-006-9061-4

18 Y. Tang, S. Yang, N. Zhang and J. Zhang, Cellulose, 21, 335 (2014), https://doi.org/10.1007/s10570-013-0158-2

9 H. Chen, "Biotechnology of Lignocellulose: Theory and Practice", Springer, Netherlands, 2014, pp. 27, https://link.springer.com/content/pdf/10.1007/97894-007-6898-7.pdf

20 P. Lu and Y. L. Hsieh, Carbohyd. Polym., 87, 564 (2012), https://doi.org/10.1016/j.carbpol.2011.08.022

21 Q. Wu, Y. Meng, K. Concha, S. Wang, Y. Li et al., Ind. Crop. Prod., 48, 28 (2013), https://doi.org/10.1016/j.indcrop.2013.03.032

22 L. Y. Mwaikambo and M. P. Ansell, J. Appl. Polym. Sci., $\quad$ 84, $2222 \quad$ (2002), https://doi.org/10.1002/app.10460

23 J. I. Morán, V. A. Alvarez, V. P. Cyras and A. Vázquez, Cellulose, $\quad \mathbf{1 5}, 149 \quad$ (2008), https://doi.org/10.1007/s10570-007-9145-9

24 L. Segal, J. J. Creely, A. E. Martin and C. M. Conrad, Text. Res. J., 29, 786 (1959), https://doi.org/10.1177/004051755902901003

${ }^{25}$ H. Kargarzadeh, I. Ahmad, I. Abdullah, A. Dufresne, S. Y. Zainudin et al., Cellulose, 19, 855 (2012), https://doi.org/10.1007/s10570-012-9684-6
26 H. A. Silvério, W. P. F. Neto, N. O. Dantas and D. Pasquini, Ind. Crop. Prod., 44, 427 (2013), https://doi.org/10.1016/j.indcrop.2012.10.014

27 R. Zuluaga, J. L. Putaux, A. Restrepo, I. Mondragon and P. Gañán, Cellulose, 14, 585 (2007), https://doi.org/10.1007/s10570-007-9118-z

${ }_{28}$ J. X. Sun, F. Xu, Z. C. Geng, X. F. Sun and R. C. Sun, J. Appl. Polym. Sci., 97, 322 (2005), https://doi.org/10.1002/app.21728

${ }^{29}$ S. Elanthikkala, U. Gopalakrishnapanicker, S. Varghese and J. T. Guthrie, Carbohyd. Polym., 80, 852 (2010), https://doi.org/10.1016/j.carbpol.2009.12.043

${ }^{30}$ H. Yu, Z. Qin, B. Liang, N. Liu, Z. Zhou et al., J. Mater. Chem. A, 1, 3938 (2013), https://doi.org/10.1039/c3ta01150j

31 L. K. Kian, M. Jawaid, H. Ariffin and O. Y. Alothman, Int. J. Biol. Macromol., 103, 931 (2017), https://doi.org/10.1016/j.ijbiomac.2017.05.135

32 S. Bano and Y. S. Negi, Carbohyd. Polym., 157, 1041

(2017), https://doi.org/10.1016/j.carbpol.2016.10.069

33 E. M. Teixeira, A. C. Corrêa, A. Manzoli, F. L. Leite, C. R. Oliveira et al., Cellulose, 17, 595 (2010), https://doi.org/10.1007/s10570-010-9403-0

34 A. Ronda, A. Pérez, I. Iañez, G. Blázquez and M. Calero, Process Saf. Environ. Prot., 109, 140 (2017), https://doi.org/10.1016/j.psep.2017.03.037

35 J. Xie, C. Y. Hse, C. F. Hoop, T. Hu, J. Qi et al., Carbohyd. Polym., 151, $725 \quad$ (2016), https://doi.org/10.1016/j.carbpol.2016.06.011

${ }^{36}$ M. Singh, A. Kaushik and D. Ahuja, Carbohyd. Polym., $\quad$ 150, $48 \quad$ (2016) https://doi.org/10.1016/j.carbpol.2016.04.109

37 M. Roman and W. T. Winter, Biomacromolecules, 5, 1671 (2004), https://doi.org/10.1021/bm034519+ 